\title{
Análise de práticas de Educação Ambiental em Escolas Públicas do Município de Olinda - Pernambuco
}

Analysis of Environmental Education Practices in Public Schools in the Municipality of Olinda Pernambuco

Análisis de las prácticas de educación ambiental en las escuelas públicas del Municipio de Olinda Pernambuco

Jamile Maria Pereira Bastos Lira de Vasconcelos ORCID: https://orcid.org/0000-0002-0898-0643 Secretaria de Educação e Esportes de Pernambuco, Brasil E-mail: jamilebastoslira@gmail.com

Dennis Bezerra Correia

ORCID: https://orcid.org/0000-0002-7782-4767 Universidade Regional do Cariri, Brasil E-mail: denniscorreia40@gmail.com

Cícero Jorge Verçosa

ORCID: https://orcid.org/0000-0002-3284-6719 Secretaria de Educação e Esportes de Pernambuco, Brasil

E-mail: cjvercosa@hotmail.com

Rafael Henrique Luciano dos Santos

ORCID: https://orcid.org/0000-0001-6968-6803 Secretaria de Educação e Esportes de Pernambuco, Brasil E-mail: rafaelhenrique.bio@gmail.com Francileide Vieira Figueirêdo

ORCID: https://orcid.org/0000-0002-6853-854X Universidade Regional do Cariri, Brasil E-mail: francileidevf@gmail.com

José Aglailson Oliveira da Anunciação

ORCID: https://orcid.org/0000-0003-1751-2953

Universidade Regional do Cariri, Brasil E-mail: aglailsonoliveira@gmail.com

Clêidio da Paz Cabral

ORCID: https://orcid.org/0000-0003-1825-4925 Secretaria de Educação e Esportes de Pernambuco, Brasil

E-mail: cabralbahia@hotmail.com

Allyson Francisco dos Santos

ORCID: https://orcid.org/0000-0001-8635-6398 Secretaria de Educação e Esportes de Pernambuco, Brasil E-mail: allysons@outlook.com.br

João Paulo Camilo de Oliveira

ORCID: https://orcid.org/0000-0003-0286-1149 Universidade Regional do Cariri, Brasil

E-mail: camilodeoliveirajoaopaulo35@gmail.com

Bruna Almeida de Oliveira

ORCID: https://orcid.org/0000-0003-3937-8038 Universidade Regional do Cariri, Brasil E-mail: brunalmeidaprof@gmail.com

Elizângela Beneval Bento

ORCID: https://orcid.org/0000-0002-7516-9711 Universidade Regional do Cariri, Brasil E-mail: elizangelaeliz@yahoo.com.br

Maria Eliana Vieira Figueroa

ORCID: https://orcid.org/0000-0002-0049-4456 Secretaria de Educação e Esportes de Pernambuco, Brasil E-mail: elianavfigueroa1@gmail.com

Pedro Hudson Rodrigues Teixeira

ORCID: https://orcid.org/0000-0001-5909-7642 Universidade Regional do Cariri, Brasil E-mail: pedrohudson@yahoo.com.br 


\begin{abstract}
Resumo
A Educação Ambiental é um tema transversal geralmente incluído no currículo escolar nas disciplinas de Ciências e Geografia do ensino fundamental. O presente trabalho aborda as práticas e os entraves relacionados à Educação Ambiental (EA) na rede municipal de ensino do município de Olinda-PE. Para tal, procurou-se na literatura suporte para uma pesquisa empírica e analisando as práticas pedagógicas desenvolvidas em escolas da rede municipal e em setores públicos do município responsável por práticas de EA. Optou-se por pesquisas qualitativa e quantitativa através de entrevistas semiestruturadas com gestores e professores, além de observações diretas em departamentos responsáveis pelo ensino na rede pública. Os resultados revelam que a EA no município de Olinda necessita de políticas públicas que invistam em projetos contínuos de formação do estudante em uma EA transformadora e que a temática socioambiental precisa estar presente no currículo escolar de forma interdisciplinar. Foi possível identificar um descompasso entre o que os aportes teóricos tratam sobre EA e o que vem sendo feito na prática em algumas escolas do município de Olinda. Palavras-chave: Educação ambiental; Práticas pedagógicas; Preservação ambiental.
\end{abstract}

\begin{abstract}
Environmental Education is a transversal theme usually included in the school curriculum in Science and Geography subjects in elementary school. This work addresses the practices and barriers related to Environmental Education (EE) in the municipal education network in the city of Olinda-PE. To this end, the literature searched for support for an empirical research and analyzing the pedagogical practices developed in municipal schools and in public sectors of the municipality responsible for EE practices. We opted for qualitative and quantitative research through semi-structured interviews with managers and teachers, as well as direct observations in departments responsible for teaching in the public network. The results reveal that EE in the municipality of Olinda needs public policies that invest in continuous projects for the education of students in a transformative EE and that the socio-environmental theme needs to be present in the school curriculum in an interdisciplinary way. It was possible to identify a mismatch between what the theoretical contributions deal with EE and what has been done in practice in some schools in the city of Olinda.
\end{abstract}

Keywords: Environmental education; Pedagogical practices; Environmental preservation.

\title{
Resumen
}

La Educación Ambiental es un tema transversal generalmente incluido en el currículo escolar en las asignaturas de Ciencias y Geografía en la escuela primaria. Este trabajo aborda las prácticas y barreras relacionadas con la Educación Ambiental (EE) en la red de educación municipal de la ciudad de Olinda-PE. Para ello, la literatura buscó sustento para una investigación empírica y análisis de las prácticas pedagógicas desarrolladas en las escuelas municipales y en los sectores públicos del municipio responsables de las prácticas de EA. Se optó por la investigación cualitativa y cuantitativa a través de entrevistas semiestructuradas con directivos y docentes, así como observaciones directas en departamentos responsables de la docencia en la red pública. Los resultados revelan que la EA en el municipio de Olinda necesita políticas públicas que inviertan en proyectos continuos para la educación de los estudiantes en una EA transformadora y que la temática socioambiental debe estar presente en el currículo escolar de manera interdisciplinaria. Se pudo identificar un desajuste entre lo que los aportes teóricos tratan sobre la EA y lo que se ha hecho en la práctica en algunas escuelas de la ciudad de Olinda.

Palabras clave: Educación ambiental; Prácticas pedagógicas; Preservación del medio ambiente.

\section{Introdução}

Na medida em que a população aumenta, há a necessidade de se produzir mais mercadorias. O aumento de poluição das áreas urbanas e de liberação de resíduos a partir do consumo gera modificações ambientais que provocam impactos muitas vezes irreparáveis ao meio ambiente.

A partir dos anos setenta do século XX, a Educação Ambiental (EA) passou a ser conhecida como prática que possibilita minimizar os efeitos da degradação ambiental, através da sensibilização das pessoas, enfatizando a necessidade de reorganizar as prioridades imediatas como a produtividade e a economia, marcadas pelo imediatismo. O presente trabalho aborda a EA sob a perspectiva de que seus preceitos podem contribuir para o contexto de uma sociedade mais justa e que considere os limites dos recursos ambientais do Planeta, priorizando práticas sustentáveis.

Os setores ligados à educação, tanto públicos quanto privados, precisam adequar suas práticas para poderem conduzir a Educação Ambiental- EA, formando cidadãos conscientes da necessidade de conservar os recursos que a natureza nos dispõe. O caso do município de Olinda-PE não é diferente. O município é conhecido pelo seu patrimônio histórico e cultural. No entanto, mesmo pelo importante patrimônio, o local sofre com problemas estruturais que causam transtornos para a população. Problemas 
como alagamentos são muito comuns no período chuvoso e é provocado tanto por falta de políticas públicas eficientes quanto por falta de informação à população sobre a importância de uma EA que favoreça na redução da degradação do ambiente.

Com esse contexto, se faz necessária uma política para o município de Olinda que invista na educação para os cuidados com o meio ambiente e que esse investimento seja expandido além do espaço escolar. A formação de um cidadão que seja multiplicador do conhecimento favorecido no ambiente escolar é essencial para que possamos sensibilizar a população sobre a urgente necessidade de conservar o que ainda nos resta dos recursos que a natureza nos dispõe.

O presente trabalho teve como objetivos analisar os entraves, as práticas e as dinâmicas dos processos pedagógicos ligados à educação ambiental em escolas públicas do município de Olinda-PE; identificar como os gestores educacionais e docentes trabalham com EA nos espaços escolares; compreender como a Secretaria de Educação direciona e coordena as ações relacionadas à educação ambiental na rede municipal de ensino; e observar como ocorre a sensibilização e práticas educativas sobre as questões ambientais em departamentos públicos ligados a EA no município.

As sociedades contemporâneas vivem cada vez mais em função das questões econômicas, priorizando o consumo exagerado. Para evitar que a degradação ambiental se agrave ainda mais, mudanças de comportamento ligadas à sustentabilidade sejam despertadas nas pessoas. Mudanças de valores que despertem a percepção de sujeito dependente da natureza.

Nesse sentido, a educação ambiental (EA) é um caminho para a conscientização da população sobre a finitude do patrimônio natural, enfatizando a importância da conscientização e mudanças de atitudes diante das práticas do cotidiano. Através de uma educação baseada na promoção ao conhecimento, o indivíduo se envolve em práticas que o levem ao despertar de novos conceitos que irão propor intervir no ambiente de forma correta.

Diante da proposta em que a EA se fundamenta, a escola é espaço de fundamental importância para a promoção ao conhecimento, lugar onde ocorre a formação do cidadão, que pode contribuir para a conscientização ambiental, fortalecendo a formação de sujeitos capazes refletirem sobre as dinâmicas socioambientais. Contudo, a EA não se restringe apenas aos espaços escolares. Pelo contrário, o conhecimento e as práticas adquiridas no ambiente escolar podem ser expandidos aos diversos locais envolvendo a sociedade na luta pela conservação do meio ambiente. Nesta perspectiva, o presente estudo poderá contribuir para a consolidação de uma educação ambiental emancipatória para o município em tela, assim como modelo para outras áreas.

Para Loureiro (2004), a educação pode tanto assumir papel de conservação da ordem social, reproduzindo ideologias e valores, como assumir papel emancipatório e comprometido com a renovação cultural e com o desenvolvimento das potencialidades do ser humano. Nesse contexto, Lima (2002) faz uma reflexão sobre as tendências emancipatórias, transformadora e conservadora da educação ambiental no ambiente escolar. Para Lima (2002), a tendência conservadora se interessa pela conservação da atual estrutura social, se caracterizando por reproduzir pensamentos conservadores e por acreditar em uma sociedade estática, que não pode ser transformada. Já a tendência transformadora e emancipatória se relaciona com o compromisso de transformação de ordem social vigente e no compromisso de renovação da sociedade e de suas relações com o meio ambiente.

De acordo com Lima (2002) e Loureiro (2004), a tendência crítica, transformadora e emancipatória é caracterizada por possuir atitudes reflexivas diante os problemas gerados pela crise civilizatória. Esse tipo de tendência é pautada num entendimento mais amplo sobre o exercício à cidadania, a democracia e emancipação. Podemos dizer que ela é uma prática indispensável à democracia e à emancipação socioambiental.

As políticas ambientais e os projetos de educação ambiental no âmbito de conscientização sobre os problemas ambientais necessitam cada vez mais de ações integradoras, que possam unir os conhecimentos científicos e as tecnologias disponíveis à ações socioambientais que atendam à população. Sendo assim, a EA deve ser um ato político e voltado para a transformação social, buscando o enfoque na perspectiva holística, que relaciona o homem, a natureza e o universo. Para Sorrentino (1998), os grandes desafios para os educadores ambientais são o resgate e o desenvolvimento de valores e 
comportamentos e o estímulo a uma visão global e crítica das questões ambientais e a promoção de um enfoque interdisciplinar que resgate e construa saberes.

Atualmente a Educação Ambiental tem como desafio garantir a construção de uma sociedade sustentável, promovendo a formação de valores éticos como cooperação, solidariedade, generosidade, tolerância, dignidade e respeito à diversidade (Carvalho, 2006). Ainda de acordo com Carvalho (2006), “a educação ambiental vai além dos conteúdos pedagógicos”, o que pressupõe a influência diretamente na vida de todos os estudantes que compreendem seus fundamentos e práticas.

As atividades práticas são aquelas que levam ao dinamismo que possibilita melhor compreensão do tema estudado. No caso da EA, ações práticas promovem à superação dos problemas ambientais através da reflexão sobre mudanças de comportamento. No entanto, alguns estudos evidenciaram que as únicas ações que envolvem a comunidade escolar "se focam em palestras e eventos comemorativos, o que de certa forma evidencia que a escola acredita que a função primordial é sensibilizar e transmitir conhecimentos" (Loureiro et al., 2006, p. 197).

Capacitações e formações continuadas devem ser propostas pelas instituições de ensino para que possibilitem aos professores mudanças de práticas educativas que visem às transformações do educando com as relações sociais que envolvem os problemas de degradação ambiental.

É nesse sentido que a EA praticada no espaço escolar se configura como um ato transformador a partir de ações práticas, dinâmicas e reflexivas que possibilitam transformação social e isso pode se refletir em ações que concretas no ambiente. Para que a EA seja um processo efetivo, ela deve promover o desenvolvimento do conhecimento e de atitudes necessárias para a melhoria da qualidade ambiental. Somente fomentando a participação comunitária, de forma articulada e consciente, um programa de EA alcançaria seus objetivos (Dias, 2004).

\section{O município de Olinda}

Segundo dados do IBGE (2010), Olinda é a terceira maior cidade de Pernambuco com 377.779 habitantes. Possui uma área de unidade territorial correspondente a 41,681 Km2, densidade demográfica de 9.063,58 hab/Km2 e IDHM correspondente a 0,735. A cidade está situada no litoral pernambucano, com bioma Mata Atlântica característica. Vizinha dos municípios de Recife e Paulista, Olinda se situa a $6 \mathrm{~km}$ ao Norte-Leste de Recife. Situado a 37 metros de altitude, com sua sede localizada nas coordenadas geográficas do município são: Latitude- 8 0' 34" Sul; Longitude: 34 51' 19" Oeste.

A Olinda ostenta quatro títulos, são eles: Patrimônio Cultural da Humanidade, Primeira Capital Brasileira da Cultura, Monumento Nacional e Cidade Ecológica. Ao longo dos últimos dois séculos o sítio histórico mantém a arquitetura adotada no início da colonização. No entanto, mesmo com a importância histórica e cultural, a cidade apresenta sérios problemas ambientais. Situações como alagamento em época chuvosa, falta de infraestrutura e saneamento básico em áreas periféricas, contaminação das praias e presença de um lixão na área urbana ainda persistem causando danos e prejuízos para a população.

Nesse contexto, se faz necessária uma educação que incentiva a conservação e preservação dos recursos naturais, históricos e culturais tão presentes no município de Olinda. Sendo assim, a Educação Ambiental proporcionada no ambiente escolar surge como uma alternativa para minimizar os efeitos de degradação ambiental.

O município é composto por 31 bairros, subdividido em 10 Regiões Político-Administrativas -RPA-. A área urbanizada da Olinda é de 36,73 km2, correspondente a 84,3\% do território do município, e 6,82 km2 de área rural, o que a torna uma cidade eminentemente urbana e densamente povoada (IBGE, 2010).

As 67 escolas da rede municipal de ensino de Olinda estão distribuídas em polos de acordo com o nível de ensino: Infantil, Fundamental I, Fundamental II e Educação de Jovens e Adultos. Dessas 67 escolas, 16 possuem turmas de Ensino Fundamental II. O objeto de análise dessa pesquisa será as dezesseis escolas de Ensino Fundamental II- Anos Finais. Isso se deve ao fator dessas escolas possuírem o maior quantitativo de alunos se comparando com as escolas que só possuem Ensino 
Infantil e Fundamental I (anos iniciais).

\section{Metodologia}

\section{Tipo de pesquisa}

Este trabalho está fundamentado em cinco etapas metodológicas para sua formulação: pesquisa bibliográfica através de aportes teóricos que deram base para a sustentação do trabalho; a pesquisa de campo com a aplicação dos questionários e entrevistas, além de observações diretas; análise documental em propostas curriculares municipais; análises dos resultados obtidos com a pesquisa.

A pesquisa bibliográfica ocorreu através de livros, periódicos, artigos científicos e outros materiais que tratem sobre temas ligados a Educação Ambiental. Foram analisados também documentos e/ou manuais que tratem da EA no munícipio de Olinda, além de análise em documentos que propõem a normatização da educação ambiental no Brasil.

Foram entrevistados através de questionários dezesseis gestores de escolas que contemplem o Ensino Fundamental II (Anos Finais) e dezesseis professores das disciplinas de Ciências e Geografia do $6^{\circ}$ (sexto) ao $9^{\circ}$ (nono) ano do ensino fundamental, com o objetivo de compreender a concepção que os entrevistados possuem sobre EA e como eles trabalham os temas referentes à sustentabilidade e ao meio ambiente. As perguntas foram estruturadas de forma a obter informações sobre as práticas educativas, como os trabalhos são conduzidos no ambiente escolar e como a comunidade escolar participa da elaboração e execução de atividades que sensibilizem os alunos sobre as questões ambientais.

Para as entrevistas com os professores foram aplicados questionários elaborados previamente com 21 (vinte e uma) perguntas e objetivas e questões que possibilitaram obter informações que caracterizem o espaço educativo, os recursos didáticos, a inserção da Educação Ambiental no currículo, o apoio e incentivo às práticas que favoreçam a interdisciplinaridade, a formação continuada dos professores na área e os entraves para a efetivação de uma educação transformadora em que o professor haja como um mediador do processo de formação do educando. Para os gestores escolares o foi composto por 20 (vinte) perguntas. O questionário foi planejado visando às diversas relações no processo educativo e procurando observar a formação dos professores.

A pesquisa teve como universo de análise 16 (dezesseis) Escolas Municipais localizadas em Regiões PolíticoAdministrativas diferentes e na zona urbana da cidade de Olinda. Nas escolas foram entrevistados os professores das disciplinas de Ciências e Geografia de turmas do $6^{\circ}$ ao $9^{\circ}$ ano.

Além das entrevistas com professores e gestores, foi visitado o Departamento de Ensino Fundamental da Secretaria de Educação de Olinda (SEDO) responsável pelos projetos e ensino. Foi analisado como os técnicos direcionam os projetos educacionais na rede municipal de ensino e como ocorre o incentivo ao docente para as práticas de EA. Para a investigação foram realizadas observações diretas a fim de investigar como o município coordena e realiza as atividades relacionadas à EA. Além de analisar os projetos, foram analisadas a ocorrência de formação continuada dos docentes em EA, a proposta curricular do município com temas sobre sustentabilidade e o incentivo às práticas sustentáveis nos espaços educativos.

Foi realizada também uma visita ao Centro de Educação Ambiental Espaço Bonsucesso na Secretaria do Meio Ambiente de Olinda, a fim de observar como os responsáveis pelo setor coordenam e direcionam as atividades relacionadas à EA com as escolas do município, com alunos e professores.

\section{Resultados e Discussão}

Foi possível identificar que $100 \%$ dos gestores informaram que no Projeto Político Pedagógico de suas escolas, existe proposta de implementação de trabalhos de EA. Identificamos ainda que $95 \%$ dos pesquisados acreditam que os estudantes de 
suas escolas podem adquirir conhecimentos no espaço escolar e serem multiplicadores dos saberes, podendo socializar o que foi aprendido para além dos muros da escola. O que ratifica a importância da EA enquanto uma prática constante nos ambientes educacionais. Assim sendo, observa-se no Quadro 1, os seguintes aspectos considerados com a obtenção dos resultados.

Quadro 1- Breve descrição dos resultados das entrevistas com Gestores.

\begin{tabular}{|l|l|}
\hline \multicolumn{2}{|c|}{ POSITIVOS } \\
\hline $\begin{array}{l}\text { A maioria dos gestores possui mais de dez anos de experiência na } \\
\text { função }\end{array}$ & Concepções superficiais ou fragmentadas sobre os princípios da EA \\
\hline Desenvolvem-se trabalhos em EA mensalmente & Significativa rotatividade de professores \\
\hline $\begin{array}{l}\text { A maioria dos coordenadores pedagógicos participa ativamente de } \\
\text { projetos voltados à EA }\end{array}$ & Baixa participação dos profissionais em formações continuadas \\
\hline $\begin{array}{l}\text { Disponibilidade de material didático em EA nas unidades escolares } \\
\text { estudadas }\end{array}$ & $\begin{array}{l}\text { Investimentos não chegam à escola para aquisição de outros } \\
\text { materiais pedagógicos }\end{array}$ \\
\hline Interação com da comunidade com atividades escolares & Ausência de exemplos de atividades em parceria com a comunidade \\
\hline Realização de projetos escolares integradores durante o ano letivo & Ausência de recursos tecnológicos para atividades pedagógicas \\
\hline
\end{tabular}

Fonte: Autores.

Foram entrevistados 16 professores de Ciências e Geografia da rede municipal de ensino de Olinda: oito professores de Ciências e oito Professores de Geografia. As questões apresentadas aos entrevistados referem-se ao perfil de cada professor, com a intenção de conhecer um pouco sobre a vida profissional de cada um e de como é a rotina escolar e as dinâmicas nas aulas que envolvem a EA.

A utilização de metodologias diversas nas aulas de EA pode tornar as aulas mais atrativas para os estudantes, tornando-os mais ativos no processo de aprendizagem e assim estimulando-os a investigar e propor soluções para os problemas existentes no seu entorno.

Ao se trabalhar com EA a escola precisa promover a consciência ambiental aliando as questões sociais, culturais e ambientais. Para isso, é importante a utilização de práticas educativas criativas, rompendo com o modelo tradicional de ensino, onde o estudante é apenas um espectador e buscar estratégias que estimulem autonomia e o protagonismo estudantil. Sendo assim, observa-se no Quadro 2, os seguintes aspectos considerados com a obtenção dos resultados.

Quadro 2- Breve descrição dos resultados das entrevistas com os Professores.

\begin{tabular}{|l|l|}
\hline \multicolumn{2}{|c|}{ POSITIVOS } \\
\hline $\begin{array}{l}\text { Maioria dos docentes é efetivo na rede municipal de ensino, o que } \\
\text { contribui para diminuir a rotatividade de professores. }\end{array}$ & $\begin{array}{l}\text { Maioria dos docentes é efetivo na rede municipal de ensino, o que } \\
\text { contribui para diminuir a rotatividade de professores. }\end{array}$ \\
\hline Predomínio de concepções conservadoras sobre EA. & Predomínio de concepções conservadoras sobre EA. \\
\hline $\begin{array}{l}\text { Formação acadêmica de acordo com o componente curricular na } \\
\text { qual leciona. }\end{array}$ & $\begin{array}{l}\text { Formação acadêmica de acordo com o componente curricular na } \\
\text { qual leciona. }\end{array}$ \\
\hline $\begin{array}{l}\text { Aulas puramente expositivas. } \\
\text { Os docentes acreditam numa EA transformadora e com isso } \\
\text { desenvolvem trabalhos que auxiliam na formação do cidadão } \\
\text { voltados para EA. }\end{array}$ & $\begin{array}{l}\text { Os docentes acreditam numa EA transformadora e com isso } \\
\text { voltados para EA. }\end{array}$ \\
\hline Ausência de formação continuada em EA. & Ausência de formação continuada em EA. \\
\hline
\end{tabular}

Fonte: Autores. 
O cenário descrito no Quadro 2 permite-nos observar um descompasso entre a concepção dos entrevistados e suas práticas. Quando muitos aspectos considerados positivos são confrontados com outros negativos. Assim podemos considerar que isso se deve ao fato de que a EA no município de Olinda deve ser um trabalho em conjunto que envolve não apenas professor e aluno, mas sim um conjunto de indivíduos nos quais participam da formação formal (gestores municipais, secretaria de educação, gestores escolares, professores, alunos e famílias). À medida que cada indivíduo envolvido no processo educativo cumprir com o dever que lhe cabe, os entraves deixam de existir. Para isso é necessário engajamento e compromisso com a formação cidadã.

\section{Ações de Educação Ambiental com estudantes das Escolas Públicas do Município de Olinda}

A EA nas escolas públicas de Olinda ocorre através de ações desenvolvidas nos espaços escolares de acordo com as bases curriculares e por projetos (feira de ciências, seminários, palestras) desenvolvidos pelas instituições de ensino e socialização dos trabalhos feitos nas escolas para na Mostra Educacional Socioambiental (MESAM). Para estimular práticas de EA a SEDO vem desenvolvendo projetos anuais com temáticas socioambientais e para isso, nos últimos dois anos, tem realizado capacitações com os docentes das disciplinas de Ciências e Geografia para que eles tenham possam realizar trabalhos nas suas escolas e depois socializarem na MESAM. O evento conta com a exposição de trabalhos das escolas participantes. Os trabalhos são diversificados e abordam temas como a água, o reflorestamento, a reciclagem, sustentabilidade e preservação de mangues. As crianças trabalham em diversos formatos: apresentações culturais, fotos, material audiovisual, exposição de maquetes, jogos, música e artesanato.

No entanto, mesmo existindo formações com finalidade de auxiliar professores a desenvolverem projetos com suas turmas sobre as temáticas socioambientais, compreendemos que a MESAM poderia ser estendido para maior quantidade de docentes e estudantes uma vez que acreditamos que as temáticas socioambientais devem ser trabalhadas de forma interdisciplinar, agregando docentes das mais diversas formações. Percebemos que o fato de existirem na base curricular do município temas ligados à EA apenas nos componentes curriculares de geografia e Ciências, faz com que apenas os professores dessas disciplinas recebam capacitações para o desenvolvimento de projetos socioambientais.

O Centro de Educação Ambiental Bonsucesso (CEA) é outro recurso disponibilizado por um órgão público municipal- Secretaria de Meio Ambiente - que tem como objetivo realizar práticas educativas em relação ao Meio Ambiente. É um espaço público que pode receber visita de estudantes de escolas públicas e privadas, além da própria população.

A rotina do CEA envolve a visitação de estudantes de escolas do município de Olinda, capacitações de professores e é aberta à visitação ao público. As instituições de ensino que sabem do trabalho do CEA e querem levar seus alunos, agendam a visitação e marcam o dia da visita. Ao chegarem ao local, os estudantes são recepcionados e levados para conhecerem o local. Em cada parte do centro os estudantes realizam atividades que envolvem palestras e oficinas.

Percebe-se que o CEA é um importante local para a formação do estudante sobre as questões ambientais. No entanto, nos momentos das visitas para a obtenção de informações para essa pesquisa, estavam havendo formação de professores e a maioria deles argumentou que "não tinha conhecimento do espaço", "não sabia da existência de oficinas para os estudantes", "que a SEDO precisaria divulgar mais o CEA e disponibilizar transporte para a condução dos estudantes até o local".

Portanto, percebe-se que poucas escolas têm acesso ao CEA. A falta de informação sobre o local e transporte para condução dos estudantes são fatores que impossibilitam os estudantes conhecerem esse espaço tão importante para a EA.

\section{Considerações Finais}

Diante dos dados obtidos e analisados, constatamos que gestores escolares e professores apresentam conhecimento fragmentado e ideias conservacionistas sobre EA, e isso reflete em suas práticas pedagógicas que não se caracterizam emancipatórias. Percebemos que as instituições escolares precisam adequar suas metodologias para trabalhar EA de forma interdisciplinar e não como um conteúdo presente somente nos componentes curriculares de Ciências e Geografia. Porém, essa visão tradicional das temáticas socioambientais deve-se à própria proposta da base curricular do município de Olinda que entende EA como uma temática a ser trabalhada apenas nessas disciplinas. A falta de uma proposta de EA interdisciplinar desde a base curricular estimula o pensamento de que questões socioambientais só podem ser trabalhadas em determinadas disciplinas. 
Mesmo com a necessidade de trabalhar a EA, muitas instituições de ensino trabalham ainda com ideias conservacionistas sobre EA e alguns profissionais alegam que não possuem formação acadêmica e não participam de formações continuadas que os capacitem para o desenvolvimento de atividades práticas que facilitem a compreensão do educando para o tema. Mesmo acontecendo momentos de projetos ou feira de ciências que tratem de temas que envolvam a EA, muitos professores têm dificuldade de problematizar criticamente as situações. Isso se deve ao fato da falta de um olhar para a EA de forma crítica e politizada.

Foi possível percebermos que os profissionais responsáveis pela educação municipal (gestores, professores, equipes responsáveis por projetos educacionais) precisam não somente se atualizar em EA, mas também em teoria pedagógica crítica, problematizadora e emancipadora.

Observamos que o município de Olinda possui recursos e locais apropriados para o desenvolvimento de uma EA crítica e emancipatória, no entanto não possui uma política de EA que incentive uma educação interdisciplinar. Exemplo disso existe o CEA que é um importante instrumento para práticas de EA e nem todas as escolas têm acesso por falta de informação e conhecimento sobre o local. Além do CEA, outros locais de Olinda têm capacidade para práticas de EA e não são usados pela maioria das escolas e muitos docentes alegam a falta de transporte para levar os alunos. Com isso, percebemos a falta de mais investimento e comprometimento dos órgãos responsáveis pela educação pública municipal de Olinda.

Podemos identificar um descompasso entre o que os aportes teóricos tratam sobre EA e o que vem sendo feito na prática em algumas escolas do município de Olinda. É necessário que haja engajamento de todas as instituições de ensino, que todos os gestores e todos os professores estejam recebendo apoio e incentivo para as práticas aconteçam de forma satisfatória. Gestores e Professores necessitam de formação adequada e permanente. Não se faz uma educação de qualidade se todos os responsáveis não estão plenamente envolvidos no processo educativo.

Tendo em vista os problemas ambientais ocasionados pela ação antrópica, acreditamos que a formação continuada dos docentes em temas ambientais e a EA voltada para a transformação social do cidadão crítico e reflexivo sobre as questões ambientais, podem ser fator importante na mudança de comportamento dos cidadãos, além de contribuir para que os conhecimentos adquiridos no ambiente escolar possam ser expandidos aos diversos locais, envolvendo a sociedade na luta pela sustentabilidade. No caso do município de Olinda a formação de cidadãos que conservam os recursos do ambiente e expandem essa visão de conservação para além dos limites da escola, pode contribuir para minimizar os diversos problemas ambientais que acontecem no município.

Percebemos que a maioria dos entraves encontrados nesse se remete a falta de políticas públicas voltadas para uma EA transformadora. A gestão municipal precisa implementar projetos que envolvam todas as escolas em projetos contínuos de EA, incentivando, capacitando profissionais e dando todo suporte necessário para que os docentes possam trabalhar com seus estudantes. Assim, uma grande parte da população poderá participar de ações de sensibilização sobre problemas consequentes da degradação ambiental, possibilitando assim a conservação dos recursos ambientais e a melhoria da qualidade de vida.

O processo de aprendizagem em EA deve estar voltado para potencializar a criatividade, o senso crítico, a transformação e a mudança de hábitos. Para isso, a escola precisa ser o espaço onde haja interação entre os indivíduos que estão dentro e no entorno dela, para que tudo que seja vivenciado, aprendido e socializado no espaço escolar possa ultrapassar os seus muros e atinjam positivamente a população.

\section{Referências}

Bardin, L. (2011). Análise de conteúdo. São Paulo: Edições 70. Brasil (2014). Manual de enfrentamento à violência contra a pessoa idosa. Brasília: Secretaria de Direitos Humanos da Presidência da República. 
Bomfim, A. M., \& Piccolo, F. D. educação ambiental crítica: para além do positivismo e aquém da metafísica critical environmental education: beyond positivism and below of the metaphysical. Anais. Florianópolis: Associação Brasileira de Pesquisa em Educação em Ciências.

Brasil. Resolução CONAMA nº 001 de 1986.

Nacionais, I. A. P. C. (1998). terceiro e quarto ciclos do Ensino Fundamental. Brasília: MEC-Secretaria de Educação Fundamental.

Presidência da República. Casa civil (1999). Subchefia para Assuntos Jurídicos. Lei nº 9.795, de 27 de abril de 1999.

Brasil, M. (1999). Ministério da Educação-Secretaria de Educação Média e Tecnológica-Parâmetros Curriculares Nacionais-Ensino Médio. Brasília: MEC/SEMT.

Ministério da Educação. Secretaria de Educação Média e Tecnológica. Parâmetros curriculares nacionais: ensino médio. Brasília: MEC/SEMTEC.

Brasil, L. D. D., \& da Educação, B. (1996). Lei n ${ }^{\circ}$ 9.394/96, de 20 de dezembro de 1996. Lei de Diretrizes e Bases da Educação.

de Moura Carvalho, I. C. (2017). Educação ambiental: a formação do sujeito ecológico. Cortez Editora.

Chalita, G. (2001). Educação: a solução está no afeto. Editora Gente.

Dias, G.F. Atividades Interdisciplinares de Educação Ambiental. (2 ${ }^{\mathrm{a}}$ ed.) Global Editora e Distribuidora Ltda., 2015.

Duvoisin, I. A. (2002). A necessidade de uma visão sistêmica para a educação ambiental: conflitos entre o velho e o novo paradigmas. Educação ambiental: abordagens múltiplas. Artmed, 91-103.

Faria, E. T. (2004). O professor e as novas tecnologias. Ser professor, 4, 57-72.

Cruz, M. M. S. (2008). FREIRE, Paulo. Pedagogia da autonomia: saberes necessários à pratica educativa. São Paulo. Paz e Terra, 1996 (Coleção leitura), 166 p. Revista Entreideias: educação, cultura e sociedade, 13(13).

Gadotti, M. (1997). Caminhos da ecopedagogia. Debates socioambientais, 2(7), 19-21.

Pedagogia da Terra (2000). (5 ed.) São Paulo: Ed. Fundação Peirópolis.

Gadotti, M. (2005). A questão da educação formal/não-formal. Droit à l'education: solution à tous les problèmes sans solution. Institut International des droits de l'enfant.

Gil, A. C. (2002). Como elaborar projetos de pesquisa (Vol. 4, p. 175). São Paulo: Atlas.

Gough, A. (2013). 2 The Emergence of Environmental Education Research: A "History" of the Field. In International handbook of research on environmental education (pp. 13-22). Routledge.

GUEDES, J. C. D. S. (2006). Educação ambiental nas escolas de ensino fundamental: estudo de caso. Garanhuns: Ed. do autor, 83, $3322-3222$.

Jacobi, P. R. (2005). Educação ambiental: o desafio da construção de um pensamento crítico, complexo e reflexivo. Educação e pesquisa, 31, 233-250.

Jones, C. (2010). Interdisciplinary approach-advantages, disadvantages, and the future benefits of interdisciplinary studies. Essai, 7(1), 26.

Knorst, P. A. R. (2010). Educação ambiental: um desafio para as unidades escolares. Unoesc \& Ciência-ACHS, Joaçaba, 1(2), 131-138.

Lima, G. F. D. C. (2002). Crise ambiental, educação e cidadania: os desafios da sustentabilidade emancipatória. Educação ambiental: repensando o espaço da cidadania, 2, 109-141.

Loureiro, C. F. B. (2004). Trajetória e fundamentos da educação ambiental. In Trajetória e fundamentos da educação ambiental (pp. 150-150).

Loureiro, C. F. B. (2006). Problematizando conceitos: contribuição à práxis em educação ambiental. Pensamento complexo, dialética e educação ambiental. São Paulo: Cortez, 104-161.

Machado, C \& Ruiz, J. (2009) A cidade como desenvolvimento humano sustentável. In: SOLER, A. C. (org) A cidade sustentável e o desenvolvimento humano na América Latina: temas e pesquisas. Rio Grande: Editora da FURG.

Magalhaes, T. L. (2016). Jogos de geotecnologia para o ensino de estudos ambientais no ambiente escolar: experiência de santarém (PA). Revista Brasileira de Educação Ambiental (RevBEA), 11(2), 313-323.

Lakatos, E. M., \& Marconi, M. D. A. (2000). Metodologia científica. (3 $3^{a}$. ed.) Atlas.

Maxwell, J. A. (2012). Qualitative research design: An interactive approach. Sage publications.

Souza, M. M. C., Deslandes, S. F., \& Gomes, R. (2011). Pesquisa social: teoria, método e criatividade. Editora Vozes Limitada.

Neal, P. (1995). Teaching Sustainable Development. Environmental Education, 50, 8-9.

Ollaik, L. G., \& Ziller, H. (2011). Distintas Concepções de Validade em Pesquisas Qualitativas. Anais do Encontro Nacional de Programas de Pós Graduação em Administração, 35.

Pelicioni, M.C.F. Fundamentos de educação ambiental. In: PhillipI, A.; Roméro, M.A.; Bruna, G.C. Curso de gestão ambiental. Manole, p. $459-483$, 2004. 
Research, Society and Development, v. 10, n. 14, e399101421741, 2021

(CC BY 4.0) | ISSN 2525-3409 | DOI: http://dx.doi.org/10.33448/rsd-v10i14.21741

Quintas, J. S., \& Gualda, M. J. (1995). A formação do educador para atuar no processo de gestão ambiental. Brasília: Edições IBAMA.

Reigota, M. (2017). O que é educação ambiental. Brasiliense.

Saviani, D. (2021). Pedagogia histórico-crítica: primeiras aproximações. Autores associados.

Sorrentino, M. (1998). De Tbilisi a Tessaloniki, a environmental education no Brasil. Educação, meio ambiente e cidadania: reflexões e experiências. São Paulo: SMA.

Silva, E. L., \& Menezes, E. M. (2001). Metodologia da pesquisa e elaboração de dissertação. Atual-Florianópolis: Laboratório de Ensino a Distância da UFSC.

Teixeira, J. C., Nascimento, M. C. R., \& Carrieri, A. D. P. (2012). Triangulação entre métodos na administração: gerando conversações paradigmáticas ou meras validações" convergentes"?. Revista de Administração Pública, 46, 191-220.

Tomazzeti, E. M.; Silveira, P.R.; Dalmora, \& Tomazzeti, C. M. (1998). Racionalidade, educação e gestão ambiental. Editora da UNISC. Redes, Santa Cruz do Sul, v.3, n.2, p.45-69, dez.

Tozoni-Reis, M. F. D. C. (2007). Contribuições para uma pedagogia crítica na educação ambiental: reflexões teóricas. A questão ambiental no pensamento crítico: natureza, trabalho e educação.Quartet, 177-221.

Vergara, S. C. (2006). Projetos e relatórios de pesquisa. Atlas.

Volpe, R. J., \& Suldo, S. M. (2014). Introduction to the special issue on theoretical frameworks in school psychological intervention research: Interdisciplinary perspectives and future directions. School Psychology Review, 43(2), 115-118. 